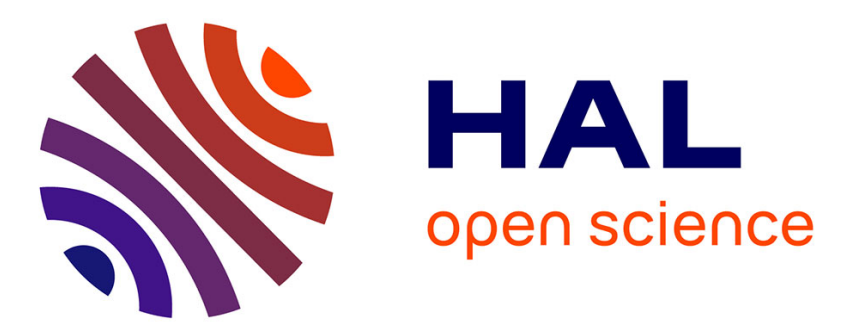

\title{
High frequency critical attenuation of sound in He3-He4 mixtures near $\mathrm{T} \lambda$
}

B. Lambert, R. Perzynski, D. Salin

\section{To cite this version:}

B. Lambert, R. Perzynski, D. Salin. High frequency critical attenuation of sound in He3-He4 mixtures near T $\lambda$. Journal de Physique Lettres, 1979, 40 (18), pp.477-479. 10.1051/jphyslet:019790040018047700 . jpa-00231669

\section{HAL Id: jpa-00231669 https://hal.science/jpa-00231669}

Submitted on 1 Jan 1979

HAL is a multi-disciplinary open access archive for the deposit and dissemination of scientific research documents, whether they are published or not. The documents may come from teaching and research institutions in France or abroad, or from public or private research centers.
L'archive ouverte pluridisciplinaire HAL, est destinée au dépôt et à la diffusion de documents scientifiques de niveau recherche, publiés ou non, émanant des établissements d'enseignement et de recherche français ou étrangers, des laboratoires publics ou privés. 


\title{
High frequency critical attenuation of sound in $\mathrm{He}^{3}-\mathrm{He}^{4}$ mixtures near $T_{\lambda}$
}

\author{
B. Lambert, R. Perzynski and D. Salin \\ Laboratoire d'Ultrasons (*), Université Pierre-et-Marie-Curie, Tour 13, 4, place Jussieu, 75230 Paris Cedex 05, France
}

(Reçu le 7 juin 1979, accepté le 20 juillet 1979)

\begin{abstract}
Résumé. - Nous avons mesuré l'atténuation critique du son à $1,1 \mathrm{GHz}$ dans des mélanges $\mathrm{He}^{3}-\mathrm{He}^{4}$ de concentrations molaires d' $\mathrm{He}^{3}: 0,06,0,20$ et 0,24 . Les résultats au-dessus de la transition de phase normale-superfluide sont analysés avec les mêmes fonctions d'échelle que celles utilisées dans 1 ' $\mathrm{He}^{4}$ pur à des fréquences dans la gamme $\mathrm{du} \mathrm{kHz}$
\end{abstract}

\begin{abstract}
We have measured the critical attenuation of sound at $1.1 \mathrm{GHz}$ in $\mathrm{He}^{3}-\mathrm{He}^{4}$ mixtures of $0.06,0.20$ and 0.24 molar $\mathrm{He}^{3}$ concentrations. The results above the superfluid-normal transition are scaled with the same scaling function used in the $\mathrm{kHz}$ frequency range for pure $\mathrm{He}^{4}$.
\end{abstract}

Recent experimental results on the critical attenuation of sound in pure helium 4 around $T_{\lambda}$, at both low frequencies $[1,2]\left({ }^{1}\right)(v \leqslant 1 \mathrm{MHz})$ and high frequencies [3] $(\sim 1 \mathrm{GHz})$ have helped specify the different contributions to the attenuation. At $\mathrm{GHz}$ frequencies the main contribution comes from the order parameter fluctuations. On both sides of the transition, these fluctuations contribute to the attenuation in a form which is not symmetric in temperature relative to $T_{\lambda}$. This contribution takes the form :

$$
\alpha_{\mathrm{F}}=\alpha_{\lambda} \frac{\omega \tau}{c+\omega \tau}
$$

with a characteristic time $\tau=\tau_{0} t^{-x}, t=\left|1-T / T_{\lambda}\right|$ and $c$ is a constant. Such an expression fits the experimental data from $2.3 \mathrm{kHz}$ to $1.2 \mathrm{GHz}$, for $T>T_{\lambda}$.

In $\mathrm{He}^{3}-\mathrm{He}^{4}$ mixtures the $\mathrm{He}^{3}$ concentration acts as an inert variable (as the pressure along the $\lambda$ line), thus it becomes interesting to test the universality of the scaling function (1) for different mixtures. This was done recently at low frequencies $[1,4]$ $(v<45 \mathrm{MHz})$. The purpose of this paper is to extend these measurements up to $1.1 \mathrm{GHz}$; this high frequency offers an especially good opportunity to study the contribution of the fluctuation mechanism to the attenuation [3].

(*) Associated with the Centre National de la Recherche Scientifique.

$\left({ }^{1}\right)$ References [1] and [2] correspond respectively to results on $\mathrm{He}^{3}-\mathrm{He}^{4}$ mixtures and pressurized $\mathrm{He}^{4}$. Each of these papers enables results for pure $\mathrm{He}^{4}$ at $P=0$ to be obtained.
The acoustical transmission technique used and the method by which we relate the transmitted signal to the attenuation, have already been described in previous articles [3]. Because we use thin samples $(\sim 5$ to $10 \mu)$, no gravity corrections are needed.

The first results of our measurements concern the dispersion of sound velocity : within the accuracy of our measurements $(\sim 0.2 \mathrm{~m} / \mathrm{s})$, we see no critical dispersion at any concentration; this result is in agreement with our previous result in pure $\mathrm{He}^{4}[3]$ and with the fact that the critical dispersion is expected to decrease with increasing concentration $[1,4]$.

Before analysing the critical attenuation $\alpha_{c}$, we have to subtract the non critical attenuation $\alpha_{B}$ from the measured attenuation. For $T>T_{\lambda}$, we take into account the contribution of the shear viscosity and of the thermal conductivity; the increase of $\alpha_{B}$ with the $\mathrm{He}^{3}$ concentration is connected with the decrease of the density and of the velocity of sound. For $T<T_{\lambda}$, the problem is more complicated : the elementary excitations (phonons and rotons) contribute to the attenuation; this contribution is well known in pure $\mathrm{He}^{4}$ [4], it peaks at $1.5 \mathrm{~K}$ for $1 \mathrm{GHz}$. In $\mathrm{He}^{3}-\mathrm{He}^{4}$, this contribution is completely unknown at $\mathrm{GHz}$ frequencies. Therefore it is not possible for us to extract the critical attenuation for $T<T_{\lambda}$ at this frequency.

The $\lambda$ transition temperature $T_{\lambda}(X)$ is deduced from the $\mathrm{He}^{3}$ molar concentration (see table) with a maximum error of $10 \mathrm{mK}$. The accuracy of our temperature measurement is better than $1 \mathrm{mK}$; but due to the error in the determination of $T_{\lambda}(X)$, our total accuracy is worse. Also shown in the table is the 
temperature $T_{\max }$ of the small apparent maximum of the attenuation just below the transition.

Table. $-X$ is the molar $\mathrm{He}^{3}$ concentration of the mixture; $T_{\lambda}$, the temperature of the normal superfluid transition $[1,4,6] ; T_{\max }$, the temperature of the small maximum of the attenuation below the transition temperature $T_{\lambda}(X) ; \tau_{0}(X)$ is the value which gives the best fit to the data (see text).

\begin{tabular}{llccl}
\multicolumn{1}{c}{$X$} & \multicolumn{1}{c}{0} & 0.06 & 0.20 & \multicolumn{1}{c}{0.24} \\
- & - & - & - & \multicolumn{1}{c}{-} \\
$T_{\lambda}$ & 2.172 & 2.085 & 1.875 & $1.805 \mathrm{~K}$ \\
$T_{\max }$ & 2.169 & 2.070 & 1.860 & $1.775 \mathrm{~K}$ \\
$\tau_{0}(X)$ & 1.5 & 2.2 & 4.0 & $5.2 \times 10^{-12} \mathrm{~s}$
\end{tabular}

Later on we only present experimental results for the normal phase. The value of the critical attenuation at the transition $\alpha_{\lambda_{c}}$ is a decreasing function of $X$. We present in figure 1 experimental value $\alpha_{\mathrm{c}} / \alpha_{\lambda \mathrm{c}}$, for

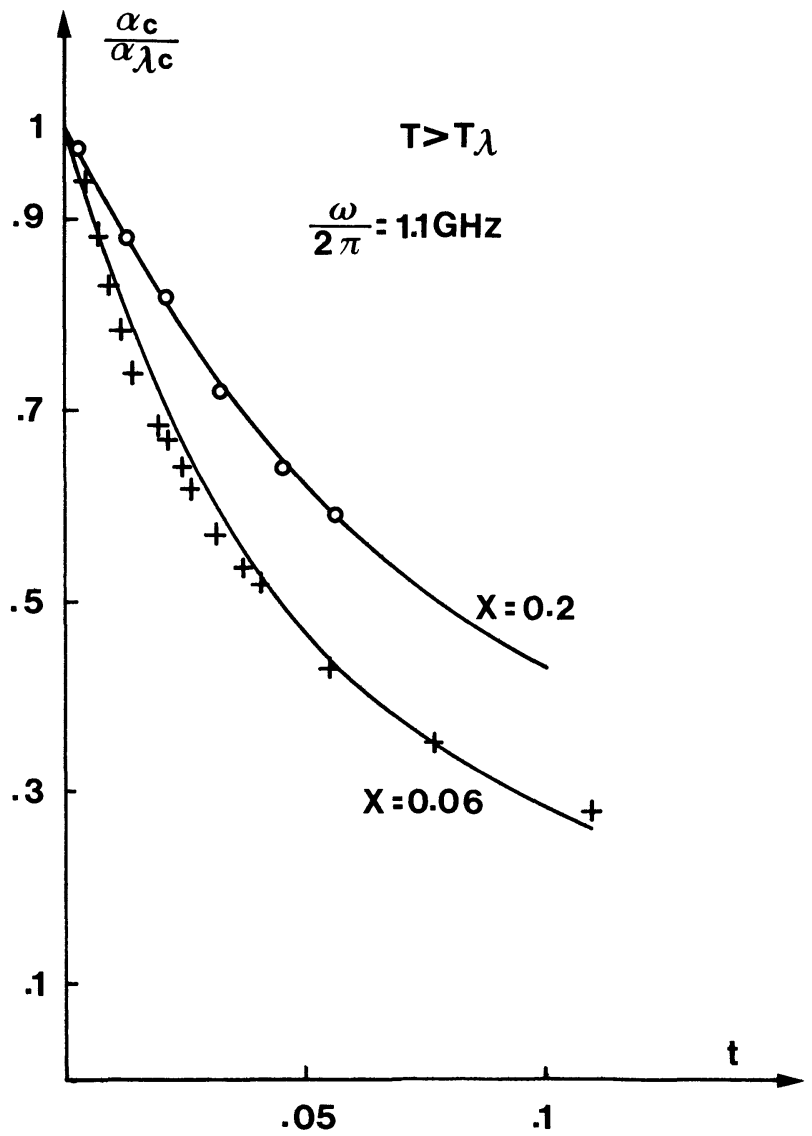

Fig. 1. - The full lines are theoretical curves (see Eq. (1)) with $x=1.13, c=0.5$ and respectively $\tau_{0}(X)=2.2 \times 10^{-12} \mathrm{~s}$ and $\tau_{0}(X)=4.1 \times 10^{-12} \mathrm{~s}$ for $X=0.06$ and $X=0.20$ mixtures.

$T>T_{\lambda}$ for two different $\mathrm{He}^{3}-\mathrm{He}^{4}$ mixtures. In previous papers [3], we analysed our data with the characteristic time $\tau_{2}$ of a relaxation mechanism ; exp. (1) is then used with $\tau \equiv \tau_{2}, \tau_{20}=2 \times 10^{-12} \mathrm{~s}$ and $x=1.062 ; c$, which is a free parameter, is determined as $c=0.5 \pm 0.05$ for $T>T_{\lambda}$. Here we follow the procedure of reference [4] (Fig. 7) and we determine, with the experimental data from $\mathrm{kHz}$ [1] to $1.1 \mathrm{GHz}$ [3], the exponent $x$ : for pure $\mathrm{He}^{4}$ we find $x=1.13 \pm 0.05$. Using eq. (1) with $c=0.5$, we determine

$$
\tau_{0}=(1.5 \pm 0.2) \times 10^{-12} \mathrm{~s}
$$

in accordance with previous experiment [2]. We present in figure 2 the values of $\alpha_{c} / \alpha_{\lambda_{c}}$ versus $(2 \pi / \omega) t^{-x}$

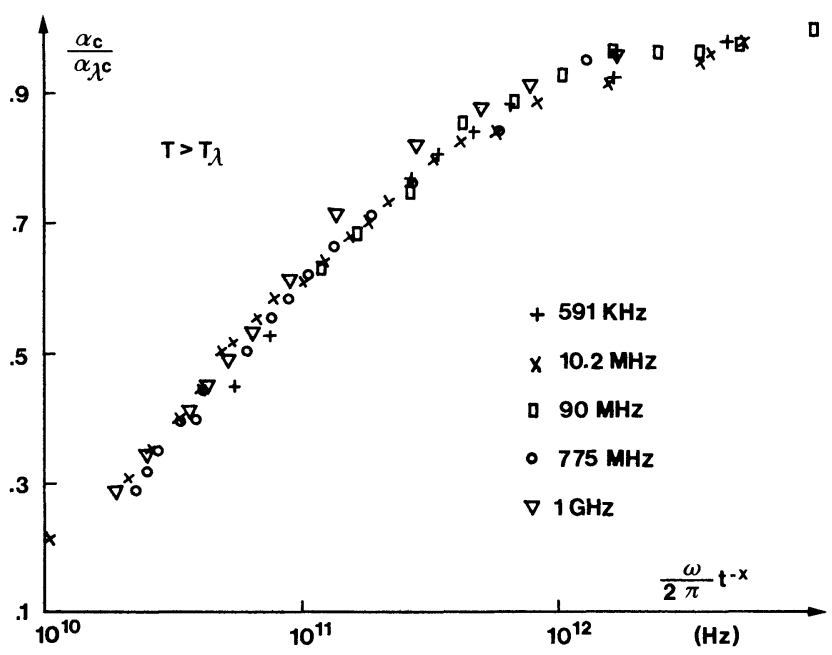

Fig. 2. - Scaling plot $\alpha_{c} / \alpha_{\lambda c}$ versus $\frac{\omega}{2 \pi} t^{-x}$ with $x=1.13$ for $T>T_{\lambda}$ and $X=0$; the frequencies are $600 \mathrm{kHz}$ [1], $10.2 \mathrm{MHz}$ [7], $90 \mathrm{MHz}$ [7], $775 \mathrm{MHz}$ [3] and $1 \mathrm{GHz}$ [5].

with $x=1.13$; this scaling plot illustrates the satisfactory collapsing of the data onto one curve. The small scattering of the data is due to many causes such as : (i) different techniques of attenuation measurements (especially at $1 \mathrm{GHz}$ ), (ii) different estimations of non-critical attenuation $\alpha_{B}$, (iii) oscillations of $\alpha_{C}$ (see for example the data at $90 \mathrm{MHz}$ ) due to the variations of the sound velocity.

We use the same procedure for $\mathrm{He}^{3}-\mathrm{He}^{4}$ mixtures ; for instance our results at $1.1 \mathrm{GHz}$ for $X=0.06$, are fitted with the results for $X=0.07$ [1] and $X=0.05$ [4] at lower frequencies with an exponent $x=1.13 \pm 0.05$. It has been mentioned [4] that this exponent slightly increases with $X$ (e.g. $1.19 \pm 0.05$ for $X=0.366)$; we are not able to determine this small increase in our experiment event at $X=0.20$; at least this small increase is of the order of magnitude of the accuracy. The exponent we use to fit our data is then $x=1.13$ for all concentrations $(X=0 ; X=0.06 ; X=0.20$; $X=0.24)$; the corresponding values of $\tau_{0}(X)$ which best fit the data are given in the table. In figure 1 , the full lines represent the value of the scaling function (1) for the corresponding mixtures : these scaling functions are in reasonable agreement with the experimental data. Finally we have to mention that in $\mathrm{He}^{3}-\mathrm{He}^{4}$ mixtures another dissipation process may contribute to the attenuation of sound : it is the mass 
diffusion $\left(\alpha_{\mathrm{D}}\right)$ for which we have no theoretical expression in the critical regime. In pure $\mathrm{He}^{4}$, where there is no mass diffusion, we analyse our data with a fluctuations contribution. In $\mathrm{He}^{3}-\mathrm{He}^{4}$ mixtures it is possible to analyse the data in the same way. Therefore we can say that it is possible to make the assumption [4] that the mass diffusion contribution, if it exists, can be described by a function of the same form as the fluctuations.

Conclusion. - We have measured the critical attenuation of sound at $1.1 \mathrm{GHz}$ in $\mathrm{He}^{3}-\mathrm{He}^{4}$ mixtures. Above the transition, the data are fitted with the same scaling function from $2.3 \mathrm{kHz}$ to $1.1 \mathrm{GHz}$.

\section{References}

[1] Buchal, C. and Pobell, F., Phys. Rev. B 14 (1976) 1103.

[2] Carey, R., Buchal, C. and Pobell, F., Phys. Rev. B 16 (1977) 3133.

[3] Lambert, B., Perzynski, R. and Salin, D., Phys. Rev. B 19 (1979) ; J. Physique Colloq. 39 (1978) C6-148.

[4] Roe, D. B., Meyer, H. and Ikushima, A., J. Low Temp. Phys. 32 (1978) 67.
[5] Imai, J. S. and RudNick, I., Phys. Rev. Lett. 22 (1969) 694.

[6] The Physics of Liquid and Solid Helium. Part 1, Ed. by K. H. Bennemann and J. B. Ketterson (John Wiley and Sons, New York) 1976, see table 21, p. 125.

[7] Tozaki, K. I. and Ixushima, A., J. Low Temp. Phys. 32 (1978) 379. 